\title{
Crack mechanisms in concrete - from micro to macro scale
}

\author{
Marta Słowik ${ }^{1}$, Piet Stroeven², Amanda Akram ${ }^{3}$ \\ ${ }^{I}$ Department of Structural Engineering; Faculty of Civil Engineering and Architecture; \\ Lublin University of Technology; 40 Nadbystrzycka Street, 20-618 Lublin, Poland; \\ m.slowik@pollub.pl iD 0000-0001-9627-3625 \\ ${ }^{2}$ Faculty of Civil Engineering and Geosciences; Delft University of Technology; \\ Stevinweg 1,2628 CN Delft, the Netherlands; \\ p.stroeven@tudelft.nl (iD)0000-0003-1283-112X \\ ${ }^{3}$ Department of Structural Engineering; Faculty of Civil Engineering and Architecture; \\ Lublin University of Technology; 40 Nadbystrzycka Street, 20-618 Lublin, Poland; \\ a.akram@pollub.pl iD 0000-0001-5619-2927
}

\begin{abstract}
The paper discusses a fictitious crack model of concrete in tension proposed by Hillerborg. This model presents a concept that illustrates the mechanism of crack initiation and its propagation in concrete on meso-level. It has proven to be a very useful tool for practical use, for both numerical and experimental research. The model was derived from findings on crack mechanisms on more advanced micro- and macro-scale, as presented in this paper. One of the paramount issues regarding crack analysis is the influence of aggregate size on mechanical and fracture parameters of concrete, and also on micro-crack development and associated macro-crack formation. Although significant progress in recognizing crack mechanisms in concrete has been achieved, there are still some aspects that should be studied in depth, for example the role of aggregate particles on crack development. This problem is analysed in the paper as well.
\end{abstract}

Keywords: concrete, crack mechanisms, fictitious crack model

\section{Introduction}

Cracking is a major aspect of concrete behaviour. The internal structure of hardened concrete is intensely micro-cracked before loading. Once loaded, the further developed crack structure is exposed to environmental influences which endanger its structural integrity. Under loading one may observe the growth of micro-cracks, which, upon further load increase, coalesce until they form a macro-crack. At still higher loadings, the macro-crack can grow and spread which may result in material fracture. Taking into account that concrete is a brittle material, the analysis of cracking mechanisms in concrete, on both micro- and macro-level, is of paramount importance in the knowledge of concrete structures. 


\section{Micro-level analysis}

Concrete is generally intensely cracked in the so-called virgin state. In normal-strength concrete, a major part of these micro-cracks is predominately situated in the surfaces of aggregate grains, while its dispersion and orientation is quite 'random' on engineering level. These cracks are the result of high stresses due to evaporation of pore water. Loading occurs which lead to growth and coalescence of these micro-cracks that yield global damage characteristics typical for the type and intensity of loading. Such load-crack evolution processes have been successfully explained - at least qualitatively - by the concepts of elastic material. Examples based on Timoshenko's elastic stress solution for an inclusion (i.e., the aggregate grain) in a semi-infinite body have been employed for this purpose in the case of completely bonded or partly debonded cylindrical grains ([1]-[5], among others). For the direct tension case, this reveals crack extension/growth in the particle-matrix interface around the zenith zones of the particle. At a certain extension, the crack leaves the interface to grow further perpendicularly to the loading direction. For a group of particles in concrete this leads to a multitude of out-of-plane cracks roughly perpendicular to the loading direction. For further crack growth, out-of-plane coalescence takes place in the fracture process zone (Fig. 1).
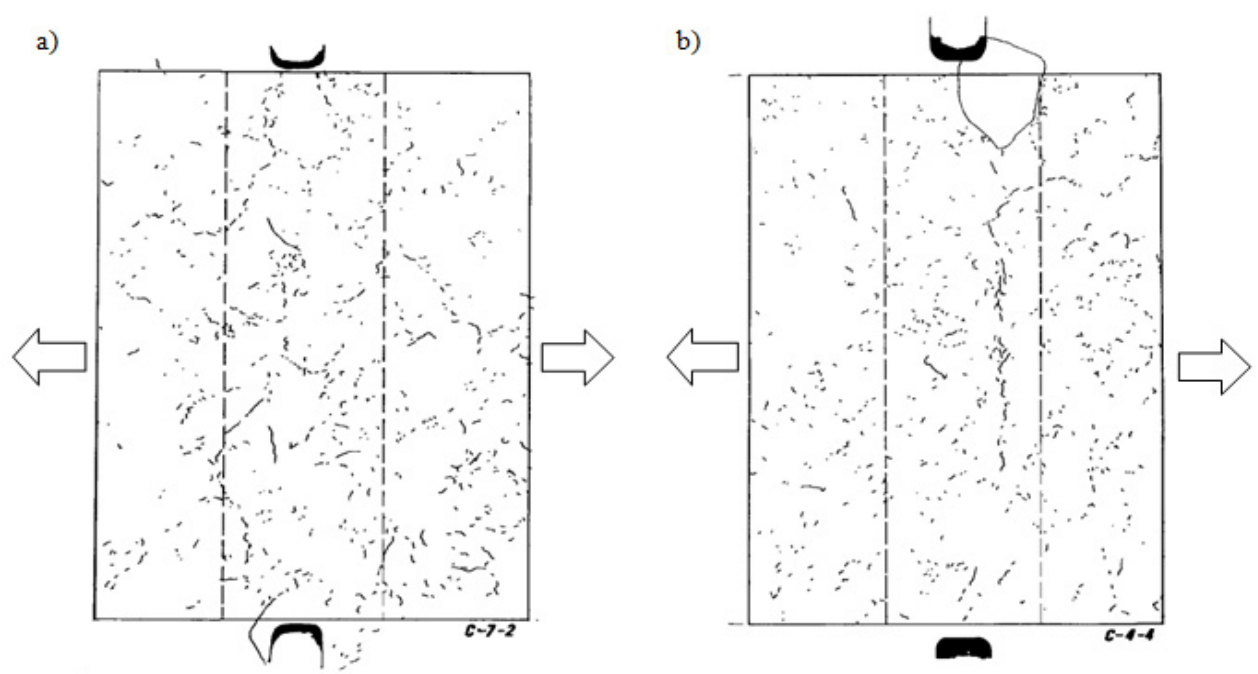

Fig. 1. Damage states in vertical sections of the central part of two-sided notched prismatic concrete specimen (with $50 \mathrm{~mm}$ between the notches, visible at top and bottom) subjected to continuously increasing uniaxial tensile strains (in horizontal direction): a) stress state about three quarters of ultimate, and b) about halfway, both along the descending branch of the stress-strain curve. Contrast was improved by a fluorescent spray and thereupon photographed under illumination by UV light. Observable crack patters were eventually hand-copied. For additional experimental details, see [6]. Above, one can observe the fracture process zone in which the final fracture path is developing during yielding of the specimen. Source: [6]

In direct 'vertical' compression, equatorial zones are subjected to tensile stresses, leading to crack growth/coalescence at the interface. The similar action happens for a large group of aggregate particles outside the tri-axially compressed zones in zenith areas of the particles. Material tends to slip along the slopes of these compressed cone-shaped zones. This is, however, a secondary phenomenon, because the zones are also pre-cracked in axial direction. So, the slip takes place along the so called 'en échelon' crack arrays, thereby stimulating growth/ 
coalescence of axial cracking at the tops of the cones. This process of growth/coalescence of axial crack continues until the fracture, and ultimately, fracture process zones are formed. Figure 2 shows the stages of this process.

a)

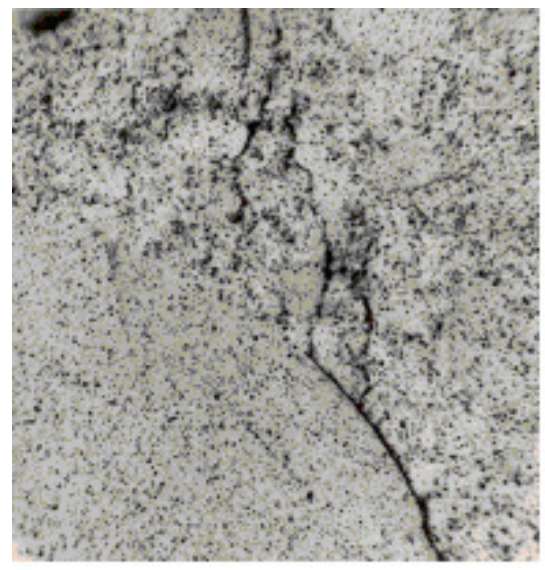

c)

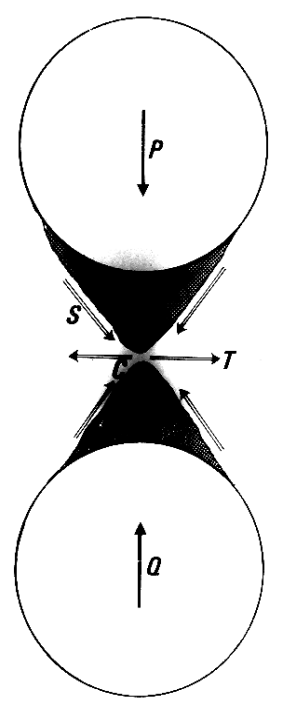

b)

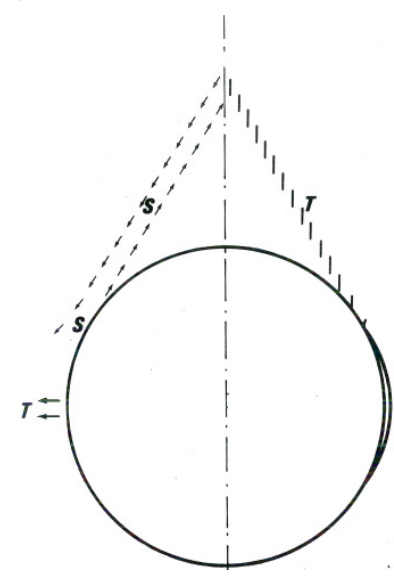

d)

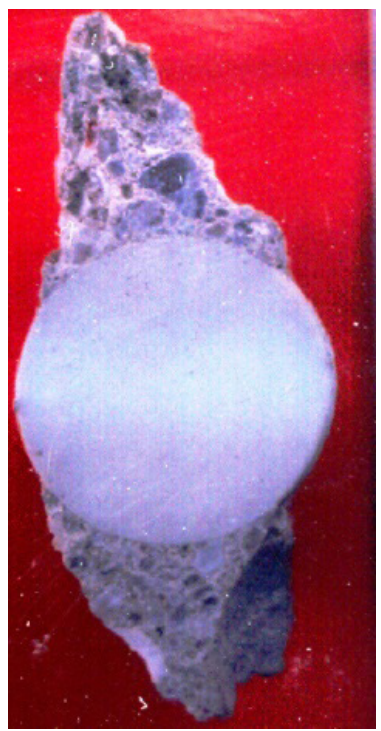

Fig. 2. Crack mechanisms in concrete in direct compression. Under increasing loading, particles (also of gravel or sand) are ultimately completely released from material body. a) interface crack of a large spherical grain enters matrix, where vertically oriented surfaces of smaller particles are pre-cracked in an "en échelon" array, shown by the model in b). The effect of the slip on structure formation in vicinity of particle ( $P, Q$ - compressive loads, $S$ - shear, $T$ - tension) is depicted in c). These conically-shaped elements are found among the debris at full collapse of the specimen d). Source: [5], [7]-[11] 


\section{Macro level analysis}

Concrete is a brittle material, unable to resist the high tensile stresses that are important when considering cracking. The low tensile capacity can be attributed to the high stress concentrations in concrete under loading, so that a relatively high stress level is observed in some parts of the specimen, whereas other parts are subjected to low stress. The higher strain concentration under loading is observed in an active zone of the specimen, where microscopic cracks tend to grow and coalesce (Fig. 3b). This zone is called the fracture process zone (FPZ) and it is often referred to as a progressive micro-cracking zone between the real crack and the non-cracked portion of concrete (Fig. 3a).

Micro-cracks in the fracture process zone run not linearly but over tortuous paths due to the heterogeneity of concrete. In the composite structure of concrete, there is hardened cement matrix with pores and micro-cracks, 'randomly' distributed aggregate particles, and an interfacial transition zone (ITZ). The ITZ is a weak area between cement matrix and aggregate; therefore, this is the place where micro-cracks start developing. Development of cracks is connected with the process of energy dissipation. From energetic point of view, the weakest zones in the heterogeneous structure of the concrete composite material are subjected to the processes of crack initiation and propagation. In normal-strength concrete it can be observed that cracks concentrate along weak interfaces surrounding the aggregate grains, and then join and propagate through the cement matrix, as discussed above. When the aggregate is weaker than cement matrix, like in high strength concrete or lightweight concrete, cracks also propagate through the aggregate grains. Thus, we can observe more brittle character of failure, e.g., in high-strength concrete. The example of crack path propagation obtained during the splitting tensile test is presented in Fig. 3c [12].

a)

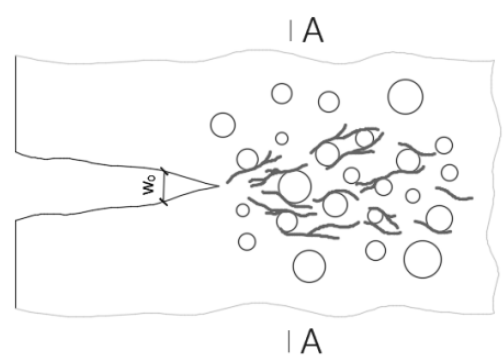

b)

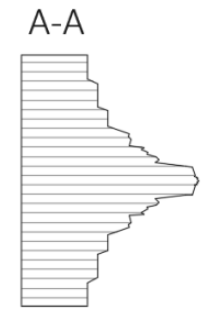

c)

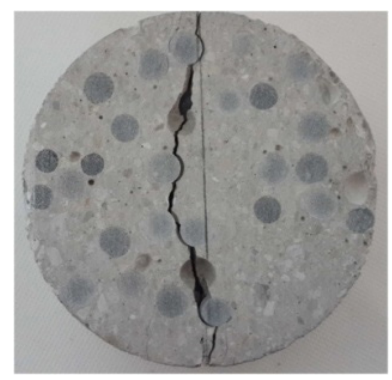

Fig. 3. Visualization of the fracture process zone, a) in the zone of progressive micro-cracking, micro-cracks are formed along weak interfaces surrounding the aggregate grains, and then join and further propagate through the cement matrix, b) the strain distribution in the fracture process zone and its vicinity, c) experiment result of a tensile splitting test. Crack tends to pass around the aggregate grains. The latter is due to existing interface cracks that may have been formed in the virgin state or developed shortly thereafter. Source: [12]

Crack mechanisms are still the subject of ongoing studies on both micro- and macrolevel. The advanced insight into crack mechanisms makes it possible to implement the findings into engineering practice. The brittle nature of concrete was the main problem in designing of concrete structures. The main mechanical parameters such as compressive strength $f_{\mathrm{c}}$, tensile strength $f_{\mathrm{ct}}$, and Young's modulus $E_{\mathrm{c}}$, have proven to be not sufficient for describing 
the phenomenon of concrete behaviour. If concrete had been a perfectly brittle material, every crack would lead to sudden, catastrophic failure. Therefore, concrete should be treated as a quasi-brittle material. Furthermore, it was realized that the concrete material reveals a complex structural response subjected to several important non-linear characteristics. Most of all, highly non-linear stress-strain behaviour leading to tensile cracking and compression crushing should be considered when analysing the failure processes in concrete structures.

One of the first theoretical models that took into consideration non-linearity of the crack propagation in concrete was the fictitious crack model proposed by Hillerborg [13]. The model was derived from researches on ductile fracture mechanics of metals. However, it was realized that the model for metals could not be directly applied to concrete. The main discrepancy was the presence of a significantly larger fracture process zone (FPZ) in concrete than in metals. The development of the FPZ made the application of linear elastic fracture mechanics not suitable for describing cracking in concrete. Hillerborg's model presents it as the zone where also strain-softening occurs (as the tensile stress decreases in the fracture process zone, whereas the strain, i.e., the crack tip opening displacement, increases). The strain-softening phenomenon is illustrated in Fig. 4. The picture also presents the stress-separation law in the post-peak range.

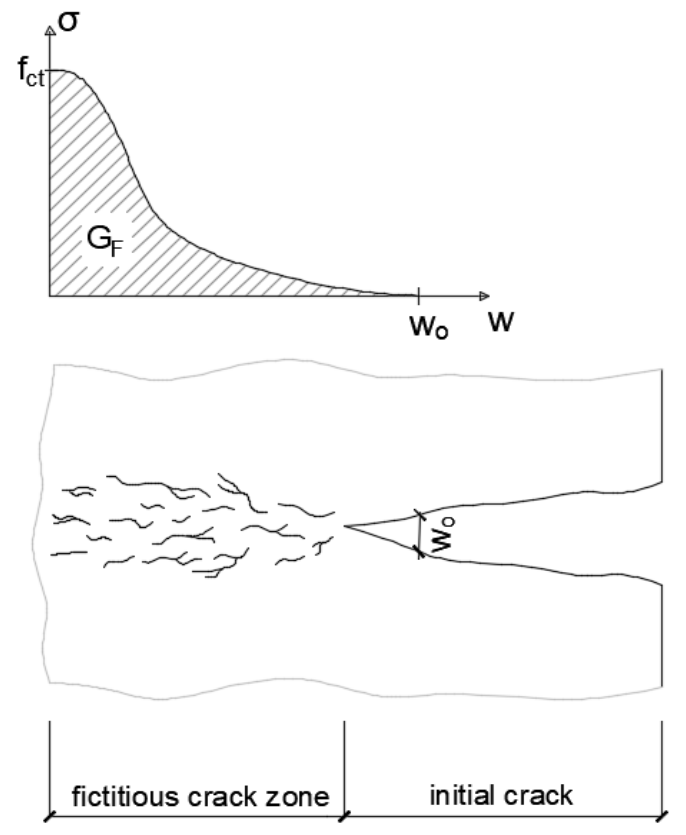

Fig. 4. Fictitious crack model for concrete in tension. Strain-softening in tension of concrete in the postpeak range is manifested by the declining stress-crack opening curve. The shaded area defines the fracture energy $G_{\mathrm{F}}$; Source: [13]

The stress-opening displacement curve $(\sigma-w)$ is a very useful tool in describing and illustrating the key elements in the fictitious crack model, such as the shape of the $\sigma-w$ curve, tensile strength $f_{\mathrm{ct}}$, and fracture energy $G_{\mathrm{F}}$. When the stress exceeds the tensile strength, crack propagation takes place in the initiation phase. For the next step of crack formation, beyond the peak load, a certain amount of energy is needed. The energy which is absorbed per unit 
area of crack face is defined as the fracture energy $G_{\mathrm{F}}$. Fracture energy is defined as the area under the descending curve of $\sigma-w$ relationship and may be estimated from

$$
G_{F}=\int_{0}^{w_{\mathrm{o}}} \sigma(w) \mathrm{d} w
$$

Fracture energy can be determined experimentally in three-point bending tests on concrete beam specimens with a notch, according to the RILEM Draft Recommendation 1985 [14]. Then, $G_{\mathrm{F}}$ is given by the area under the load-deflection relationship divided by the net cross-section of the specimen above the notch.

\section{Application of the fictitious crack model}

On the basis of the model proposed by Hillerborg and further developments in non-linear fracture mechanics ([15], [16]), the description of the tensile behaviour of concrete was codified. The design model of concrete subjected to tensile stresses was proposed in CEB FIP Model Code 1990 [17]. As tensile failure of concrete is a discrete phenomenon, the model allows describing strain softening of concrete in tension with a bi-linear stress-strain diagram for uncracked concrete and a bi-linear stress-crack opening diagram for the cracked material. The diagrams are presented in Fig. 5 where:

$G_{\mathrm{F}}-$ fracture energy $\left[\mathrm{Nm} / \mathrm{m}^{2}\right]$, which may be estimated from Eq. 2;

$w_{1}$ - crack opening [mm], which may be calculated from Eq. 3;

$w_{\mathrm{o}}-$ crack opening $[\mathrm{mm}]$ for $\sigma_{\mathrm{ct}}=0$ as given in Tab. 1 .
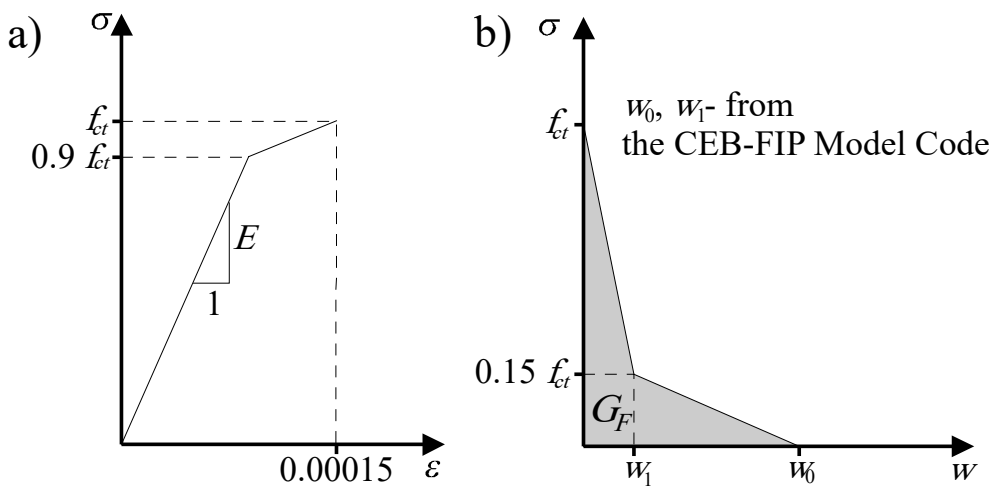

Fig. 5. Diagrams recommended in CEB-FIP Model Code1990 for the tensile zone of concrete: a) stress versus strain, b) stress versus crack opening. Source: [17]

$$
\begin{aligned}
& G_{F}=\alpha_{F} f_{c}^{0,7} \\
& w_{1}=\frac{G_{F}-22 w_{C}\left(\frac{G_{F}}{\alpha_{F}}\right)^{0.95}}{150\left(\frac{G_{F}}{\alpha_{F}}\right)^{0.95}}
\end{aligned}
$$

Fracture energy $G_{\mathrm{F}}$ and crack opening $w_{\mathrm{o}}$ were found to depend on the maximum aggregate size $D_{\max }$ [18]. This finding was taken into account in the code (see Tab. 1). 
Table 1. Coefficients $\alpha_{\mathrm{F}}$ and crack openings $w_{\mathrm{o}}$ according to CEB FIB Model Code. Source: [17]

\begin{tabular}{llll}
\hline No. & Maximum aggregate size, & Coefficient & Crack opening \\
& $D_{\max }[\mathrm{mm}]$ & $\alpha_{\mathrm{F}}$ & $w_{\mathrm{o}}[\mathrm{mm}]$ \\
\hline 1 & 8 & 4 & 0.12 \\
\hline 2 & 16 & 6 & 0.15 \\
\hline 3 & 32 & 10 & 0.25 \\
\hline
\end{tabular}

The concrete model proposed in CEB FIP Model Code [17] was successfully applied to several numerical analyses of concrete structures.

The use of the softening model in the analysis by Finite Element Method (FEM) rendered possible to describe more thoroughly fracture processes underlying the development of failure in concrete members. Also high crack resistance observed during the experiments as compared to cracking forces calculated on the basis of linear elastic theory could be properly explained [19].

The significant progress in describing size effects was possible after performing numerical simulations by means of the fictitious crack model. For various types of loading, the bigger member size, the smaller cracking forces. However, this effect is often ignored. Advanced understanding of fracture mechanics of concrete gave the possibility to rationally derive cracking forces in structural concrete members from the complete range of sizes ([20]-[22]).

Numerical simulations also helped to find a reason why the cracking moment in a lightly reinforced concrete beam is higher than in a plain concrete member ([19], [23]). Significant differences in tensile stress distribution between non-reinforced and lightly reinforced concrete beam were obtained (see Fig. 6). These differences have been noticed at load stages when strain-softening starts to develop. The numerical analysis has shown that the process of crack formation is more stable in the beam with reinforcement. Reinforcing steel bars reduce the progress in crack propagation due to the effect of bonding between concrete and the reinforcing bars. The final result is that the cracking resistance of a lightly reinforced concrete member is higher than in a plain concrete one. The comparison of tensile stress of concrete and lightly reinforced concrete beam is shown in Fig. 6 .

The performed FEM-analysis showed another phenomenon connected with numerical simulation. When the progressive micro-cracking of concrete is modeled as a smeared crack band, the width of the crack band appears as an additional parameter. This is called the width of fracture process zone $\left(w_{\mathrm{c}}\right)$ :

$$
w_{c}=\frac{2 G_{F}}{f_{c t}^{2}}\left(\frac{1}{E}-\frac{1}{E_{t}}\right)^{-1}
$$

The performed numerical analyses ([24], [25]) have shown that the width of the fracture process zone has an influence on the FEM results. The proper selection of this parameter during the numerical calculations depended on obtaining correct results by finite element method. When examining the beam presented in Fig. 6a, the analysis of the influence of the width of the fracture process zone on the results of the numerical calculations was made. Different widths were selected for modelling this zone: $w_{\mathrm{c}}=5 ; 10 ; 20 ; 26.5 ; 50$; and $100 \mathrm{~mm}$. Taking into account the minimum potential energy in a member, it may be stated that a best approach would be to select the smallest elongation within the localized micro-cracking zone ahead of the major crack. In the analysed beams, this condition occurs when $w_{\mathrm{c}}$ is $10 \mathrm{~mm}$. When one takes $w_{\mathrm{c}}=3 D_{\max }$, as proposed in the literature: [15], such assumption does not fit this criterion. Note that in the analysed beam, it would be $w_{\mathrm{c}}=100 \mathrm{~mm}$, because $D_{\max }=32 \mathrm{~mm}$. Unfortunately, so far, neither a standard method of experimental determination of the width of fracture process zone has been proposed, nor the analytical 
method has been described in depth. There are also no definite conclusions for the influence of aggregate size on the width of the fracture process zone. Therefore, there are no consistent rules how to define the width of micro-cracked zone in modelling concrete structures.

The presented examples of numerical simulations confirm that fictitious crack model can be successfully employed when analysing crack mechanism of concrete. Although several new concepts on describing concrete fracture have been proposed (e.g. [15], [26]-[29]), the "classical" Hillerborg model still finds useful application in concrete engineering (for example: [30]-[33]).

a)
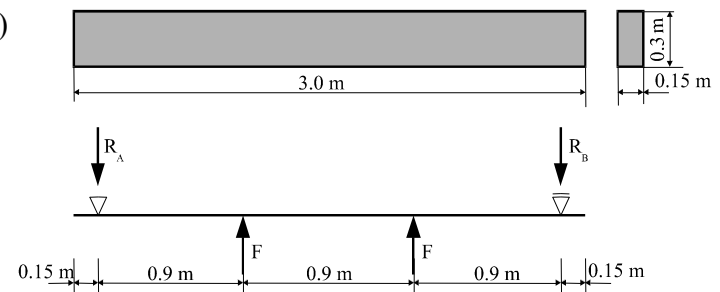

b)
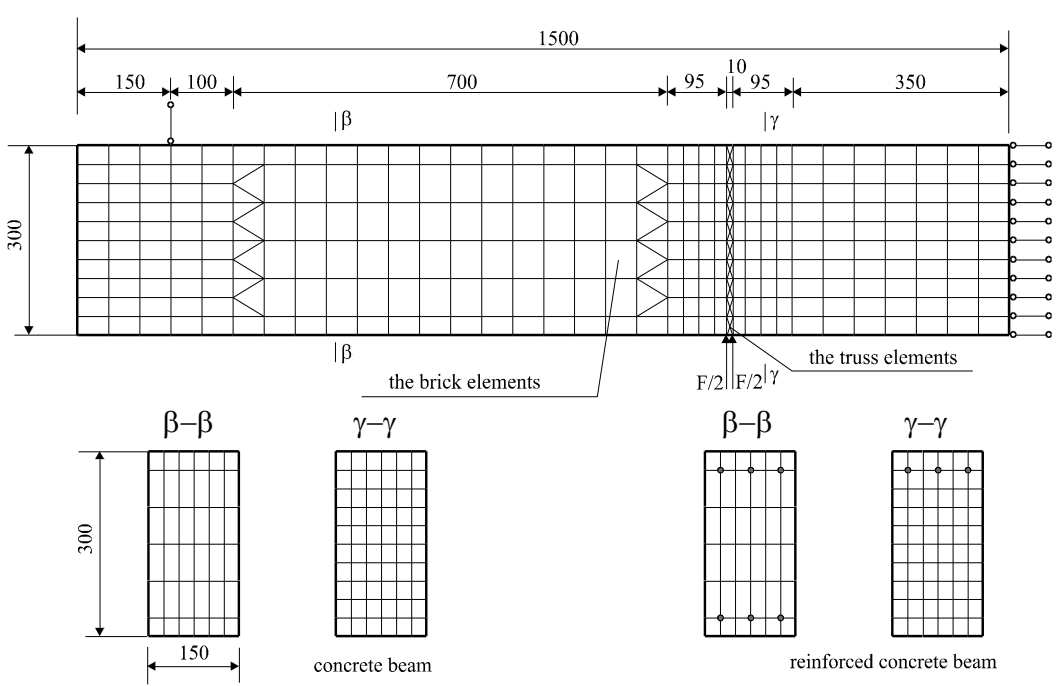

c)

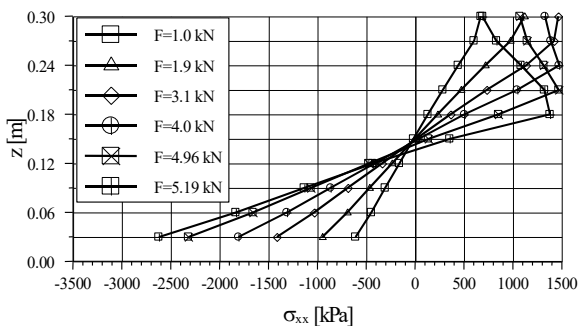

d)

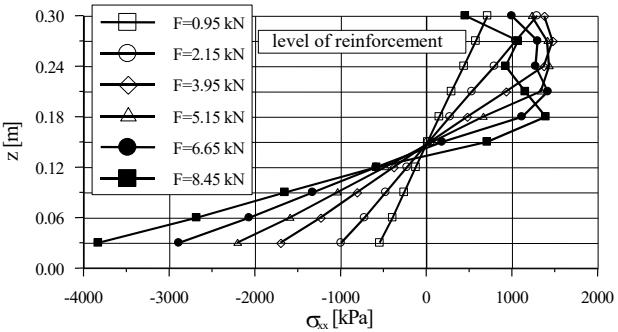

Fig. 6. The comparison of normal stress diagrams in the fracture process zone at different load stages for c) plain concrete beam, and d) for reinforced concrete beam. a) Static scheme of the beam specimen; because of the reversed load application, the tension zone and reinforcing bars are in the upper part of the beam, b) the FEM-mesh. The numerical calculations were performed as a 3D simulation on one half of the beam, since the four-point bending test is symmetrical. The fracture process zone was modelled in the region of the highest bending moment by truss elements with non-linear characteristics of the concrete; the bulk material was modelled by brick elements as elastic material. Source: [19], [23] 


\section{Conclusions}

The fictitious crack model of concrete in tension proposed by Hillerborg is a concept incorporating the mechanism of crack initiation and propagation in concrete on meso-level. This concept was found to be very useful for practical implementations, for both numerical and experimental investigations. In laboratory testing it is often denoted as the work-of-fracture method. The model was derived from the findings on crack mechanisms on more advanced micro- and macro-scale, as it was presented in this paper. One of the paramount issues connected with crack analysis is the influence of aggregate size on mechanical and fracture parameters of concrete and furthermore on micro-crack development and associated macro-crack formation. Although significant progress in recognizing crack mechanisms of concrete has been achieved, there are still some aspects that should be resolved in depth, for example the influence of aggregate particles size on crack development. This problem is supposedly associated with (sub-level) micro-crack formation resulting from the virgin state, and predominantly leading to partly debonded aggregate grains at the start of the test. The latter is definitely depending on aggregate size because a quasi-fractal phenomenon.

\section{References}

[1] Perlman A.B. and Sih G.C., "Elastostatic problems of curvilinear cracks in bonded dissimilar materials", International Journal of Engineering Science, no. 5 (II), 1967, pp. 845-867.

[2] Willis J.R., "Fracture mechanics of internal cracks", Journ. Mech. Phys. Solids, no. 19(6), 1971, pp. 353-368.

[3] Vile G.W.D., "The strength of concrete under short-term static biaxial stress", Proc. Int. Conf. Structure of Concrete. (Eds. A.E. Brooks, K. Newman). Cem. Concr. Assoc., 1968, pp. 275-288.

[4] Shah S.P. and Winter G., "Inelastic behaviour and fracture of concrete", Journ. Am. Concr. Inst., no. 63(9), 1966, pp. 925-930.

[5] Stroeven P., "Some aspects of the micromechanics of concrete", PhD Thesis, Delft University of Technology, Delft Univ. Press, 1973.

[6] Stroeven P., "Geometric probability approach to the examination of micro-cracking in plain concrete", Journal of Materials Science 14, 1979, pp. 1141-1151.

[7] Stroeven P., "Some observations on micro-cracking in concrete subjected to various loading regimes", Engineering Fracture Mechanics, vol. 35(4/5), 1990, pp. 775-782.

[8] Stroeven P., "Damage mechanisms in fiber reinforced concrete composites", in Comptes rendus des neuvième journées nationales sur les composites (Eds. J.-P. Favre, A. Vautrin), AMAC, JNC 9 (in French), 1994, pp. 925-938.

[9] Stroeven P. "Damage evolution in compressed concrete", in: Proceedings of the International Conference on Fracture (Ed. A. Carpinteri), University of Turin, Italy (on CD), 2005.

[10] Stroeven P., 50 years'focus on concrete - from meter- to nano-scale, Media Center Rotterdam, 2015.

[11] Perry C. and Gillott J.E., "The influence of mortar aggregate bond strength on the behaviour of concrete in compression", Cement and Concrete Research, vol. 7(5), 1977, pp. 553-564.

[12] Benkemoun N., Khazraji H.A., Poullain P., Choinska M. and Khelidj A., "3-D mesoscale simulation of crack-permeability coupling in the Brazilian splitting test", International Journal for Numerical and Analytical Methods in Geomechanics, vol. 42(1), 2017, pp. 1-20.

[13] Hillerborg A., Modeer M. and Petersson P.E., "Analysis of Crack Formation and Crack Growth in Concrete by Means of Fracture Mechanics and Finite Elements", Cement and Concrete Research, vol. $6,1976,773-782$. 
[14] RILEM Draft Recommendation, Determination of the fracture energy of mortar and concrete by means of three-point bent tests on notched beams, Matériaux et Constructions, vol. 18(106), 1985, pp. 258-290.

[15] Bažant Z.P. and Oh B.H., "Crack Band Theory for Fracture of Concrete", Matériaux et Constructions, vol. 16(193), 1983, pp. 155-177.

[16] Cedolin L., Poli S.D. and Iori I., "Experimental Determination of the Fracture Process Zone in Concrete", Cement and Concrete Research, vol. 13, 1983, pp. 557-567.

[17] CEB-FIP Model Code 1990, Bulletins d'information, no. 196.

[18] Kleinschrodt H.D. and Winkler H., "The Influence of the Maximum Aggregate Size and the Size of Specimen on Fracture Mechanics Parameters", Fracture Toughness and Fracture Energy of Concrete. Ed. by F.H. Wittmann, Elsevier Science Publishers B.V., Amsterdam, 1986, pp. 391-402.

[19] Słowik M., "The analysis of failure in concrete and reinforced concrete beams with different reinforcement ratio", Archive of Applied Mechanics, vol. 89, 2019, pp. 885-895.

[20] Kwon H., Zhao Z. and Shah S.P., "Effect of specimen size on fracture energy and softening curve of concrete: Part II. Inverse analysis and softening curve", Cement and Concrete Research, vol. 38 (8-9), 2008, pp. 1061-1069.

[21] Kumar S. and Bara V.S., "Size-effect of fracture parameters for crack propagation in concrete: a comparative study", Computers and Concrete, vol. 9(1), 2012, pp. 1-19.

[22] Hoover C.G. and Bažant Z.P., "Cohesive Crack, Size Effect, Crack Band and Work-of-Fracture Models Compared to Comprehensive Concrete Fracture Tests", International Journal of Fracture, vol. 187(1), 2014, pp. 133-143.

[23] Słowik M., "The analysis of Crack Formation in Concrete and Slightly Reinforced Concrete Member in Bending", in Brittle Matrix Composites 8. Edited by A.M. Brandt, V.C. Li, I.H. Marshall, Woodhead Publishing Limited, Cambridge and Zturek Research-Scientific Institute, Warsaw, 2006, pp. 351-360.

[24] Słowik M. and Błazik-Borowa E., "The Influence of Aggregate Size on the Width of Fracture Process Zone in Concrete Members", in Brittle Matrix Composites 9, Woodhead Publishing Limited, Cambridge and IFTR, Warsaw, 2009, pp. 429-438.

[25] Słowik M., "Numerical analysis of the width of fracture process zone in concrete beams", Computational Materials Science, vol. 50, 2011, pp. 1347-1352.

[26] Hu X.Z. and Wittmann F.H., "Fracture energy and fracture process zone", Materials and Structures, vol. 25, 1992, pp. 319-326.

[27] Bažant Z.P. and Planas, J., Fracture and Size Effect in Concrete and Other Quasibrittle Materials. London: CRC Press, 1998.

[28] Rossello C., Elices M. and Guinea G.V., "Fracture of model concrete: 2. Fracture energy and characteristic length", Cement and Concrete Research, vol. 36(7), 2006, pp. 1345-1353.

[29] Mechanical Behavior of Concrete, Edited by Torrenti J.M., Pijaudier-Cabot G. and Reynouard J.M., John Wiley \& Sons, Inc., 2013, pp. 63-120.

[30] Carloni C., "Analyzing bond characteristics between composites and quasi-brittle substrates in the repair of bridges and other concrete structures", Advanced Composites in Bridge Construction and Repair, vol. 3, 2014, pp. 61-93.

[31] Zhong H., Li H., Ooi E.T. and Song C., "Hydraulic fracture at the dam-foundation interface using the scaled boundary finite element method coupled with the cohesive crack model", Engineering Analysis with Boundary Elements, vol. 88, 2018, pp. 41-53. https://doi.org/10.1016/j. enganabound.2017.11.009 
[32] Carloni C., Cusatis G., Salviato M., Le J.-L., Hoover C.G. and Bažant Z.P., "Critical comparison of the boundary effect model with cohesive crack model and size effect law", Engineering Fracture Mechanics, vol. 215, 2019, pp. 193-210. https://doi.org/10.1016/j.engfracmech.2019.04.036

[33] Cornetti P., Muñoz-Reja M., Sapora A. and Carpinteri A., "Finite fracture mechanics and cohesive crack model: Weight functions vs. cohesive laws", International Journal of Solids and Structures, vol. 156-157, 2019, pp. 126-136. https://doi.org/10.3390/met9050602 
